Int. J. Dev. Biol. 52: 743-752 (2008)

doi: $10.1387 / \mathrm{ijdb} .072566 \mathrm{gc}$

\title{
Two egg-derived molecules in sperm motility initiation and fertilization in the Pacific herring (Clupea pallasi)
}

\author{
GARY N. CHERR ${ }^{1,2, *}$, MASAAKI MORISAWA ${ }^{3}$, CAROL A. VINES ${ }^{2}$, KAORU YOSHIDA $^{4}$, EDMUND H. SMITH², \\ TAKAHIRO MATSUBARA ${ }^{5}$, MURALI C. PILLAI ${ }^{6}$, FREDERICK J. GRIFFIN ${ }^{2}$ and RYUZO YANAGIMACHI ${ }^{7}$

\begin{abstract}
${ }^{1}$ Departments of Environmental Toxicology and Nutrition, University of California Davis, CA USA, ${ }^{2}$ Bodega Marine Laboratory, University of California Davis, USA, ${ }^{3}$ Department of Biology, Yamagata University, Japan, ${ }^{4}$ Biomedical Engineering Center, Toin University of Yokohama, Japan, ${ }^{5}$ Hokkaido National Fisheries Research Institute, Fisheries Research Agency, Kushiro, Hokkaido, Japan, ${ }^{6}$ Department of Biology, Sonoma State University, CA USA and 7 Institute for Biogenesis Research, University of Hawaii Medical School, Hawaii, USA
\end{abstract}

\begin{abstract}
Sperm of the Pacific herring are immotile at spawning. Two egg-derived molecules are capable of initiating sperm motility. One is herring sperm activating protein(s) (HSAPs) and the other is sperm motility initiation factor (SMIF). These two motility initiators differ in their location and association with the chorion, and in thier isoelectric points and molecular weights. In this study we have investigated the roles of these two inducers with respect to motility and fertilization. Using computer analysis of sperm motility, we found that HSAPs, as well as the Cterminal HSAPs peptide, elicit a linear motility pattern, while SMIF induced a highly circular and asymmetric pattern. HSAPs induced a two-fold increase in intracellular calcium, whereas SMIF induced a four-fold increase of motility initiation. SMIF-exposed sperm, preloaded with BAPTAAM, showed a more linear motility and this motility trajectory decreased with their fertilizing capability. The difference in intracellular calcium levels between HSAPs and SMIF is consistent with the observed linear and circular motility. In the absence of SMIF, HSAPs do not support fertilization. Fertilization is rescued in these experiments if SMIF is reintroduced. We propose that diffusible HSAPs are not essential for fertilization, but enhance sperm-egg collisions via linear motility. SMIF, which is bound to the micropylar region of the chorion, is required for fertilization and induces circular motility that is a prerequisite for sperm to enter the micropylar canal and fertilize the egg.
\end{abstract}

KEY WORDS: micropyle, intracellular calcium, sperm motility, chorion, motility initiation

\section{Introduction}

In most broadcast spawning animals, fertilization requires motile spermatozoa to locate and contact the egg. In most teleost fish, sperm are usually quiescent within the testes and seminal fluid and initiate vigorous motility upon dilution into the external medium in which spawning occurs (Morsiawa, 1994). In teleost fish sperm, an increase in intracellular calcium $\left([\mathrm{Ca} 2+]_{\mathrm{i}}\right)$, albeit through different signaling mechanisms, occurs upon motility initiation (reviewed by Darszon et al., 1999, and this issue; Hee et al., 2005; Alavi and Cosson, 2006). Four different triggers of sperm motility in teleosts have been identified: 1) a reduction in external $\mathrm{K}^{+}$upon dilution of semen initiates motility in salmonids (Morisawa et al., 1983a; Morisawa, 1985); 2) hypotonic exposure after dilution into freshwater is the trigger in non-salmonid freshwater fishes (Morisawa and Suzuki, 1980; Morisawa et al., 1983b; Krasznai et al., 2003; Morita et al., 2003); 3) hypertonic exposure initiates sperm motility in marine teleosts (Morisawa and Suzuki, 1980; Oda and Morisawa, 1993; Detweiler and Thomas, 1998); and 4) egg-associated molecules activate sperm motility in only two species (Yanagimachi and Kanoh, 1953; Yanagimachi, 1957a,b; Suzuki, 1958).

The sperm of Pacific herring are virtually immotile upon spawn-

Abbreviations used in this paper: ASW, half-strength artificial seawater; EV, Expert Vision; FSW, half-strength filtered seawater; HSAP, herring sperm activating protein; pI, isoelectric point; SMIF, sperm motility initiation factor.

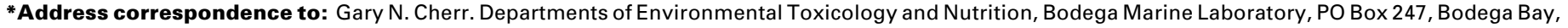
CA 94923 USA. Fax +1-707-875-2089. E-mail: gncherr@ucdavis.edu
}

Bodega Marine Laboratory contribution number 2416

Published online: 4 July 2008

$0214-6282 / 2008 / \$ 35.00$

(C) UBC Press

Printed in Spain 
A

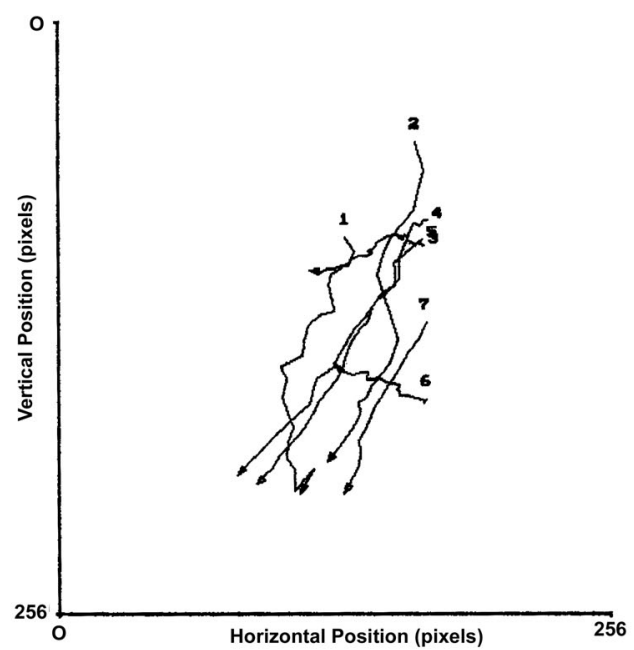

B

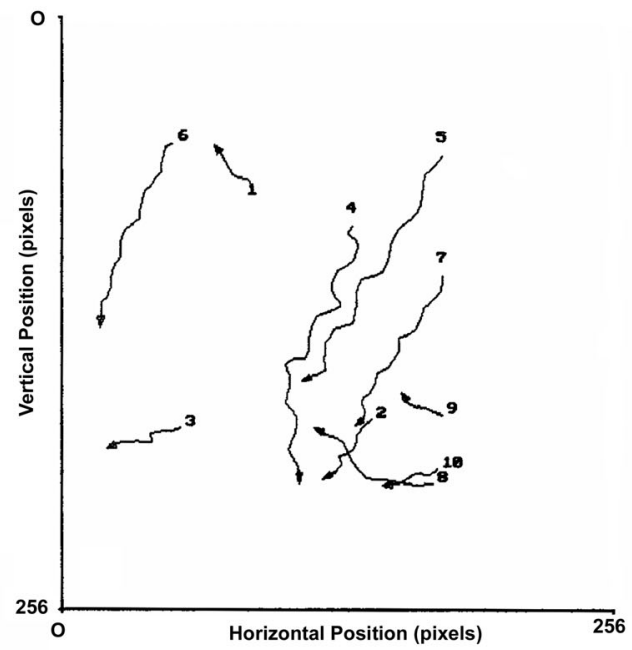

C

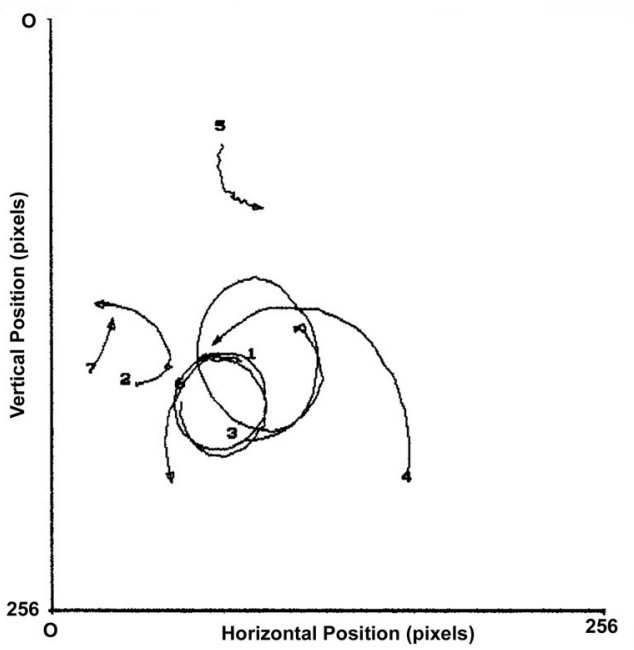

Fig. 1. Examples of digitized sperm trajectories captured using a 20x objective lens with darkfield optics using Expert Vision (EV). Individual sperm paths are numbered. (A) Paths of sperm in $\mathrm{Na}^{+}$-free artificial sea water. Linear trajectories are easily observed. (B) Paths of sperm exposed to the $C$-terminal herring sperm activating protein peptide 150 $\mu \mathrm{g} / \mathrm{ml}$ ) also show similar linear paths. (C) Paths of sperm exposed to sperm motility initiating factor $(50 \mu \mathrm{g} / \mathrm{ml})$ showing circular trajectories. ing (regardless of osmotic strength of the medium) and only become vigorously motile upon contact with the egg (Yanagimachi and Kanoh, 1953;Yanagimachi, 1957a; Yanagimachi etal., 1992). Sperm motility, fertilization, and embryonic development in herring are optimal near 1/2 strength seawater (Yanagimachi et al., 1992; Griffin et al., 1998; Vines et al., 2002). The immotility of sperm across all salinity ranges in the absence of egg-derived initiators is associated with the role of a reverse $\mathrm{Na}^{+} / \mathrm{Ca}^{2+}$ exchanger in motility initiation (Vines et al., 2002). While herring sperm can be induced to initiate motility artificially with $1 / 2$ strength sodium free artificial seawater $\left(\mathrm{Na}^{+}\right.$-free ASW; choline chloride replacing sodium chloride), natural initiation of sperm motility occurs when sperm interact with one of two egg chorionassociated molecules, sperm motility initiation factor (SMIF; Yanagimachi et al., 1992; Pillai et al., 1993; Griffin et al., 1996) or herring sperm activating proteins (HSAPs; Morsiawa et al., 1992; Oda et al., 1995; 1998; Ohtake, 2003). SMIF is a $105 \mathrm{kDa}$, basic (pl 8.1) glycoprotein that is non-diffusible and bound to the micropylar region of the chorion. When SMIF is removed from the egg using acidic seawater, eggs are rendered unfertilizable yet viable (Yanagimachi et al., 1992; Pillai et al., 1993; Griffin et al., 1996). The majority of SMIF binds to the sperm midpiece, but some is associated with the entire sperm surface (Griffin et al., 1996). In contrast to SMIF, HSAPs are acidic (pl 4.8-5.4), diffusible low molecular weight proteins (major HSAP of $8.1 \mathrm{kDa}$ ) that are localized to the outer layer of the chorion except in the micropylar region (Oda et al., 1995, 1998; Ohtake, 2003). In contrast to SMIF, HSAPs bind to the sperm head but not to the midpiece or flagellum (Yoshida, 1998). A 19 amino acid peptide from the carboxy terminus of HSAP, the "C-terminal HSAPs peptide" (also known as HSAP-E), possesses the majority of motility initiating activity (Yoshida, 1998; Ohtake, 2003).

The presence of two egg-derived molecules that initiate motility in Pacific herring sperm raises the question as to their specific roles in fertilization. In this paper, we report two different physiological responses of sperm to HSAPs and SMIF that relate to functional changes in motility. Using computer analysis of sperm motility, we show that sperm motility patterns differ dramatically between the two initiators, and we relate these differences to different intracellular calcium $\left(\left[\mathrm{Ca}^{2+}\right]_{\mathrm{i}}\right)$ increases. The differences in motility (linear versus circular) between the two initiators were directly related to the sperm's ability to enter the micropylar canal and fertilize the egg. Finally, we show that SMIF is essential for fertilization while HSAPs are not. Based on these observations, we propose a model that assigns roles for each of the egg-derived motility initiators and how they may function in concert to achieve optimal fertilization rates under natural spawning conditions.

\section{Results}

\section{HSAP- and SMIF- induced sperm motility patterns differ}

Observations of sperm motility patterns in HSAPs, or the Cterminal HSAPs peptide, appeared very similar with sperm exhibiting linear paths that were very similar to the paths of sperm in $\mathrm{Na}^{+}$-free ASW (Vines et al., 2002; this study). Digitized video analyzed by the EV system clearly showed that HSAPs and $\mathrm{Na}^{+}-$ free ASW both showed more linear motility while sperm that initiated motility in response to SMIF were much more curvilinear to circular (Fig. 1). Percent motility was calculated from the video 


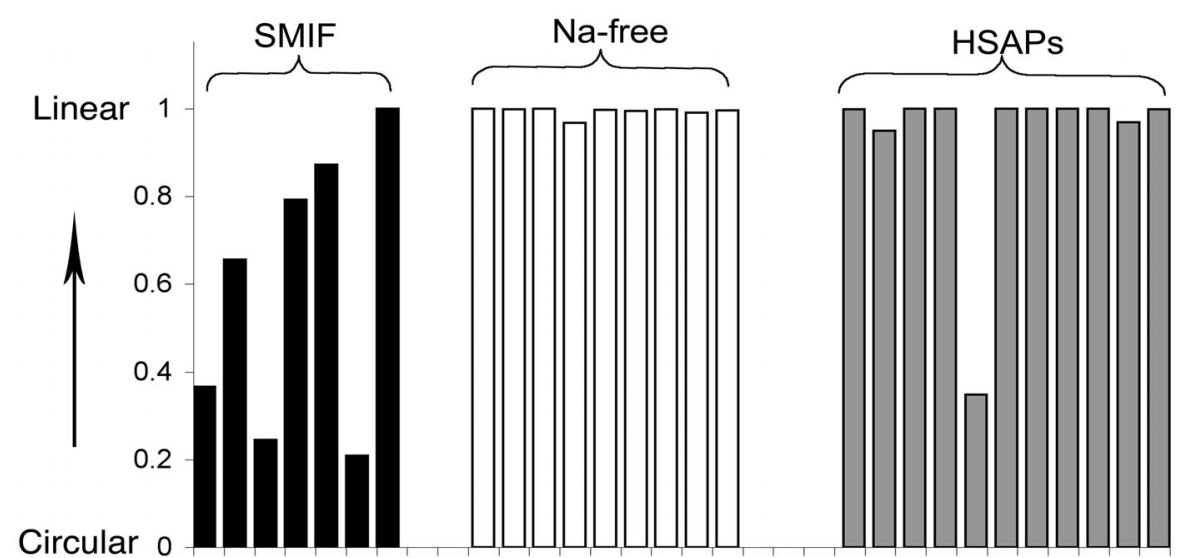

Individual Sperm Paths
Fig. 2. Net to gross displacement ratio of sperm motility initiating factor (SMIF, $50 \mu \mathrm{g} / \mathrm{ml}$ ), $\mathrm{Na}^{+}$free artificial sea-water (ASW, "Na-free") and herring sperm activating protein (HSAP, 50 $\boldsymbol{\mu} \mathbf{g} / \mathbf{m l}$ ) treated sperm. The net to gross displacement number is dimensionless between zero and one. It is an index of path "twistedness" or contortion. Simple linear movement results in a ratio of 1.0, while circular motion would result in a declining net to gross displacement ratio that approaches zero as movement completes a full circle. SMIF treated sperm were statistically different from both $\mathrm{Na}^{+}$-free $(p=0.015)$ and $\operatorname{HSAP}(p=0.013)$ treated sperm (which were not different from each other; $p=0.398$ ). capture data using 15 sec intervals; non-motile sperm were defined as those that did not move over the entire interval of analysis. Because of the path setting parameters, non-motile sperm could easily be counted while editing the path data sets. For three experiments, the percent motility for $\mathrm{Na}^{+}$-free $\mathrm{ASW}$ ranged from $91-98 \%$, HSAPs ranged from 98 to $100 \%$, and SMIF ranged from 60 to $68 \%$. For swimming speed, the mean and standard deviation of the mean for each path was extracted and a $t$ test applied. There was no statistically significant difference between treatments. With regard to direction of travel, $\mathrm{Na}^{+}$-free ASW and HSAPs were not statistically different $(p=0.342)$, however these were different from SMIF $(p=0.017)$. Rate of change of direction was not different between HSAPs and $\mathrm{Na}^{+}$-free ASW $(\rho=0.379)$. However, only $\mathrm{Na}^{+}$-free ASW was different than SMIF $(p=0.017)$.

Net to gross displacement ratios were analyzed for the smoothed path data. For a given point in a path, the net displacement is the distance along a straight line from the first point in the path to the

A

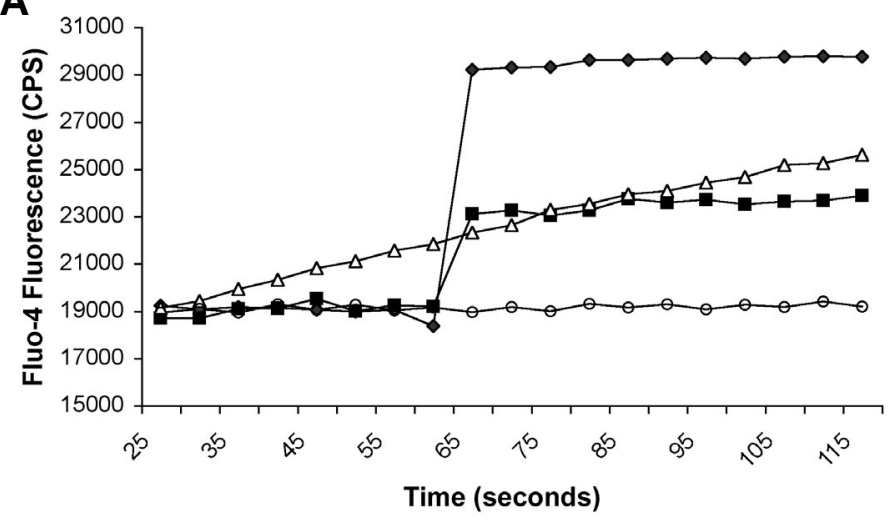

B

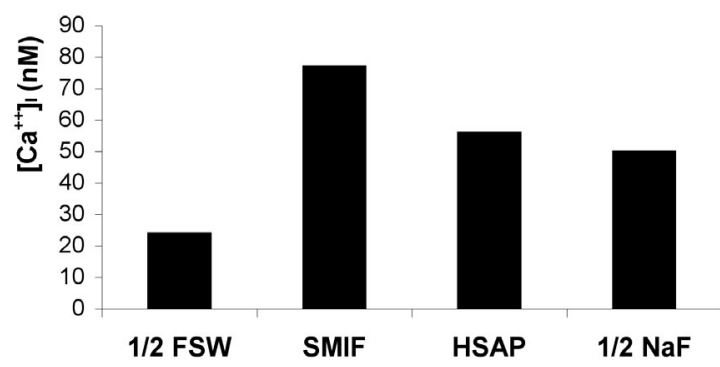

end of the path. In contrast, the gross displacement is the distance along the actual path from the first point in the path to the end of path. The net to gross displacement number is dimensionless between zero and one. It is an index of path "twistedness" or contortion, whereas simple linear movement results in a ratio of 1. Repeated circular motion would result in a declining net to gross displacement ratio that approaches zero with the progression of time. A straight line has a value of one; a path that is a perfect circle has an instantaneous value of zero after traversing a complete circle. Figure 2 shows the net to gross displacement ratios for ten randomly selected paths for each of the three treatments. Most of the ten paths for HSAPs and $\mathrm{Na}^{+}$-free ASW showed paths approaching 1.0 (linear), and there was no statistical difference between these two treatments $(p=0.398)$. However, SMIF treated sperm were clearly more circular and analysis showed that SMIF was statistically different from HSAPs and $\mathrm{Na}^{+}$-free ASW treated sperm ( $p=0.013, p=0.015$, respectively).

\section{[Ca2+] levels in sperm differ between HSAP and SMIF treat- ments $^{i}$}

The addition of HSAPs or SMIF to sperm resulted in a rapid increase in $\left[\mathrm{Ca}^{2+}\right]_{\mathrm{i}}$. HSAPs induced an approximate doubling of $\left[\mathrm{Ca}^{2+}\right]_{\mathrm{i}}(25 \mathrm{nM}$ to $55 \mathrm{nM})$ while SMIF $(50 \mu \mathrm{g} / \mathrm{ml})$ resulted in close to a $4 x$ increase (25 nM to $78 \mathrm{nM}$; Fig. $3 \mathrm{~A}, \mathrm{~B})$. HSAPs induced a $\left[\mathrm{Ca}^{2+}\right]_{\mathrm{i}}$ increase that was similar in magnitude as $\mathrm{Na}^{+}$-free ASW (Fig. 3 A,B). The C-terminal HSAPs peptide $(50 \mu \mathrm{g} / \mathrm{ml})$ induced a similar $\left[\mathrm{Ca}^{2+}\right]_{\mathrm{i}}$ response to HSAPs (data not shown).

Imaging of the change in $\left[\mathrm{Ca}^{2+}\right]_{i}$ in Fluo-3 loaded sperm, using scanning laser confocal microscopy, showed that the increase in $\left[\mathrm{Ca}^{2+}\right]_{\mathrm{i}}$ induced by HSAPs was primarily associated with the sperm head and midpiece (Fig. 4B). This is similar to what we observed for sperm treated with $\mathrm{Na}^{+}$-free ASW (Fig. 4C). With SMIF, sperm

Fig. 3. Increases in $[\mathrm{Ca} 2+]_{\mathrm{i}}$ in Fluo-4-AM loaded sperm exposed to sperm motility initiating factor (SMIF), herring sperm activating proteins (HSAPs) and Na+-free artificial sea-water (ASW). (A) Fluo-4 fluorescence in counts per second (CPS) measured in a cuvette in the fluorometer. SMIF (50 $\mathrm{gg} / \mathrm{ml}$; ), HSAPS $(50 \mu \mathrm{g} / \mathrm{ml}$; $)$ ), or control ASW (O) were added at $60 \mathrm{sec}$. For $\mathrm{Na}^{+}$-free $\mathrm{ASW}(\Delta)$, sperm were introduced into that solution at $25 \mathrm{sec}$. Both HSAPs and $\mathrm{Na}^{+}$-free ASW showed a similar response while SMIF was much greater. (B) Changes in $\left[\mathrm{Ca}^{2+}\right]_{i}$ for each treatment (compared to filtered seawater control, FSW) based on calculated intracellular concentrations. 

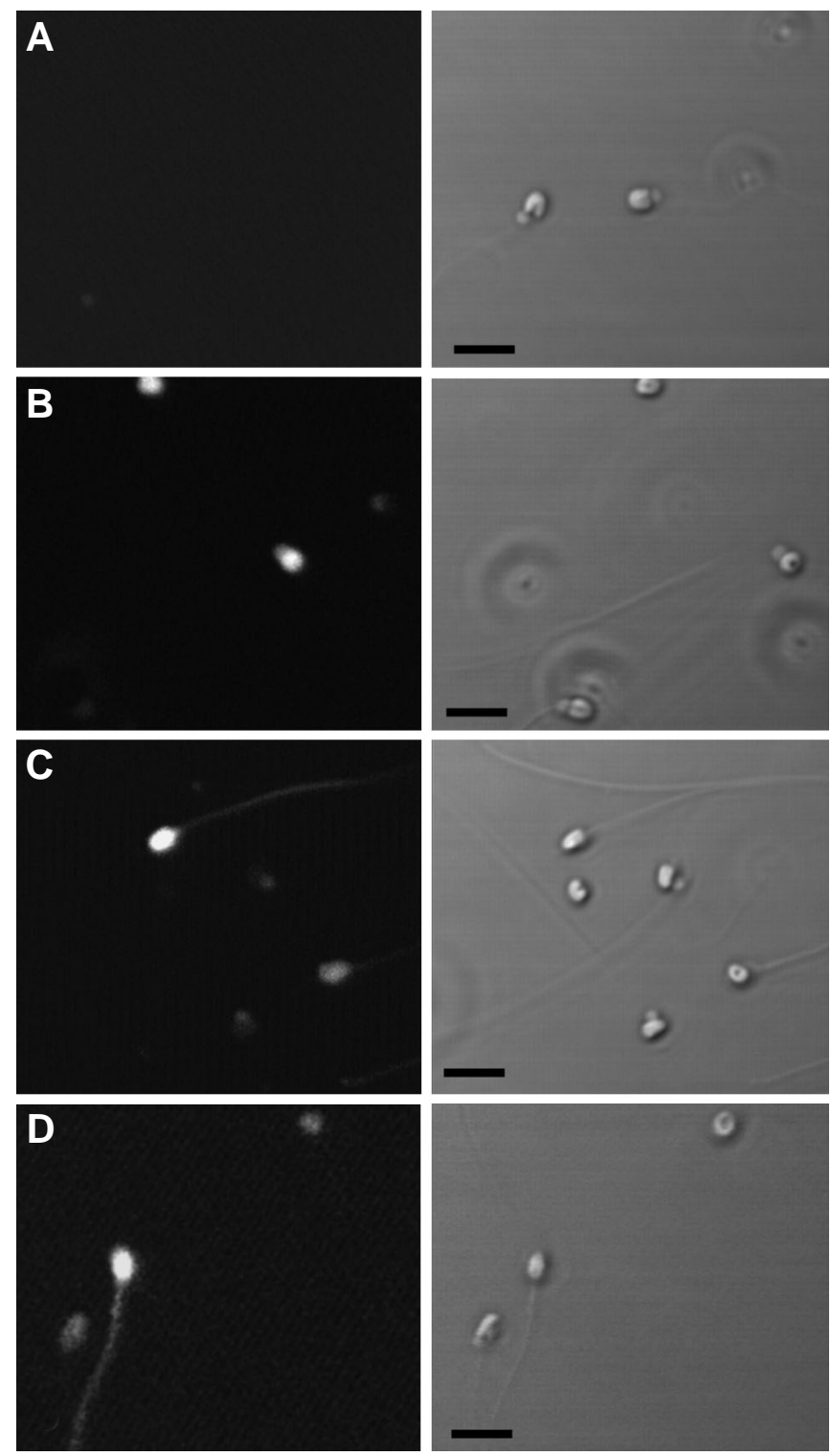

Fig. 4. Fluo-3-AM loaded sperm treated with sperm motility initiating factor (SMIF, $50 \mu \mathrm{g} / \mathrm{ml}$ ), the $C$-terminal herring sperm activating proteins (HSAPs) peptide $(50 \mu \mathrm{g} / \mathrm{ml}), \mathrm{Na}^{+}$-free artificial sea-water (ASW) and control ASW and imaged using a 60x lens with scanning laser confocal microscopy. Fluorescence images are on the left, with corresponding interference contrast images on the right (bars, $5 \mu \mathrm{m}$ ). Argon $(488 \mathrm{~nm})$ laser intensity, photomultiplier tube current, gain and contrast settings were identical for all images captured. (A) ASW treated sperm showing low $\left[\mathrm{Ca}^{2+}\right]_{i}$. (B) Sperm in $\mathrm{Na}^{+}$-free ASW show an increase in $\left[\mathrm{Ca}^{2+}\right]_{i}$ primarily in the head and midpiece regions. (C) Sperm treated with the C-terminal HSAPs peptide show increased $\left[\mathrm{Ca}^{2+}\right]_{i}$ in the head and midpiece, behaving similarly as in $\mathrm{Na}^{+}$-free ASW. (D) Sperm treated with SMIF showed a more global increase in $\left[\mathrm{Ca}^{2+}\right]_{i}$ that included the head, midpiece and flagellum.

showed a greater Fluo-3 signal than either HSAPs or $\mathrm{Na}^{+}$-free ASW (Fig. 4D), and these sperm also showed a more global increase in $\left[\mathrm{Ca}^{2+}\right]_{i}$ that included the head, midpiece, and the flagellum.

Sperm preloaded with BAPTA-AM and incubated with SMIF exhibited decreased $\left[\mathrm{Ca}^{2+}\right]_{\mathrm{i}}$ levels in response to SMIF (Fig. 5A,B). This $\left[\mathrm{Ca}^{2+}\right]_{i}$ decrease as a result of increasing BAPTA loading were in the same range as the $\left[\mathrm{Ca}^{2+}\right]_{i}$ change in response to HSAPs and $\mathrm{Na}^{+}$-free ASW treatments. BAPTA-loaded sperm (25 and $\left.50 \mu \mathrm{M}\right)$ exhibited a similar percentage of motile sperm as control (DMSO), while at $100 \mu \mathrm{M}$ BAPTA, motility was reduced. At $50 \mu \mathrm{M}$ BAPTA, sperm exposed to SMIF exhibited a much more linear motility than those sperm only exposed to SMIF and the solvent carrier (Figs. 6 $A, B)$.

\section{Role of egg-derived sperm motility initiators in fertilization}

Experiments that investigated the role for each motility initiator in fertilization success showed that HSAPs were not required for fertilization. Removal of HSAPs did not reduce fertilization success, but eggs that had SMIF removed exhibited no or very low fertilization success as reported previously (Fig. 7; Yanagimachi et al., 1992). The eggs that lacked SMIF could not be rescued by HSAPs or $\mathrm{Na}^{+}$-free ASW addition and the fertilization rates for both of these were not significantly different $(p>0.16)$ from just eggs lacking SMIF (Fig. 7). On the other hand, SMIF addition $(50 \mu \mathrm{g} / \mathrm{ml})$ to eggs that previously had SMIF removed, were partially rescued, with fertilization rates returning to about one half of control egg levels.

To determine if sperm linear motility paths were responsible for the inability of HSAPs and $\mathrm{Na}^{+}$-free ASW to increase fertilization success in eggs lacking SMIF, the following experiment was performed. BAPTA-loaded SMIF-exposed sperm (exhibiting linear motility relative to control SMIF-exposed sperm) were added to control eggs and fertilization success determined (Fig. 8). BAPTAloaded sperm showed decreased fertilization success as compared to the solvent carrier controls (0.05\% DMSO; "0" BAPTA). While $25 \mu \mathrm{M}$ BAPTA decreased fertilization rates from $61.2 \%$ to $43.8 \%, 50 \mu \mathrm{M}$ BAPTA reduced fertilization rates to $34.6 \%$. The 100 $\mu \mathrm{M}$ BAPTA concentration showed the greatest reduction in fertilization, but due to a percentage motility decrease we cannot attribute the fertilization decline solely to sperm trajectories.

\section{Discussion}

Pacific herring are an estuarine spawning fish whose sperm are unique in that they are immotile upon spawning, and it is only just prior to, or during contact with the egg chorion, that sperm initiate motility (Yanagimachi and Kanoh, 1953; Yanagimachi, 1957a,b; Yanagimachi et al., 1992; Morisawa et al., 1992). While it was originally documented in herring that sperm contact with the surface of the chorion, only in the micropylar region, is required for motility initiation (Yanagimachi and Kanoh, 1953; Yanagimachi, 1953; Yanagimachi, 1957a,b; Yanagimachi et al., 1992), more recent evidence also exists for diffusible factors from the egg that are capable of initiating motility in sperm (Morisawa et al., 1992; Oda et al., 1995). Therefore, the purpose of this study was to determine if the physiology of motility initiation with the two inducers differed, and if that resulted in differences in their role in fertilization.

\section{Sperm motility initiators from herring eggs induce different sperm trajectories}

This study shows that HSAPs and SMIF quantitatively differ greatly in the functional responses that they elicit in sperm. Com- 
A

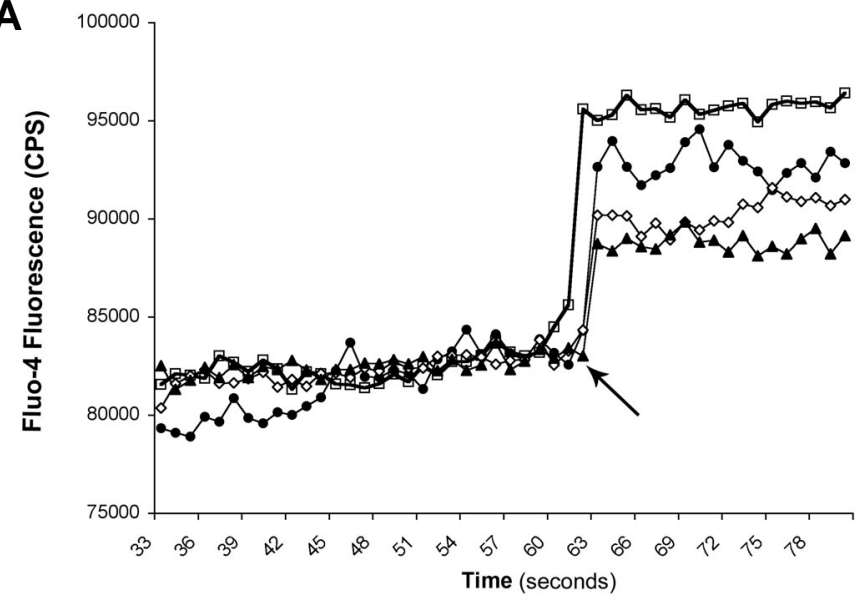

B

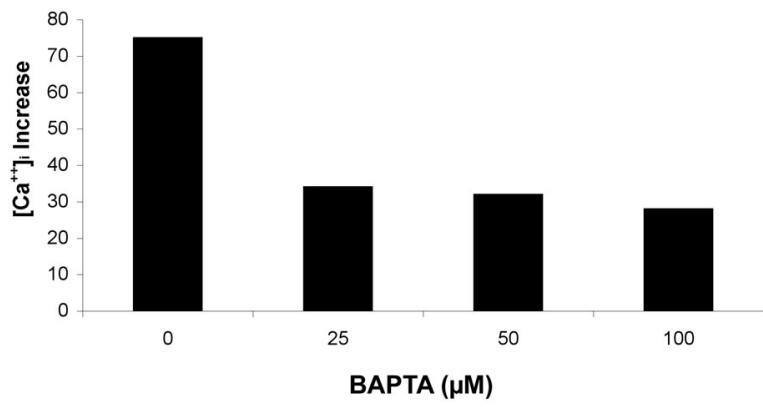

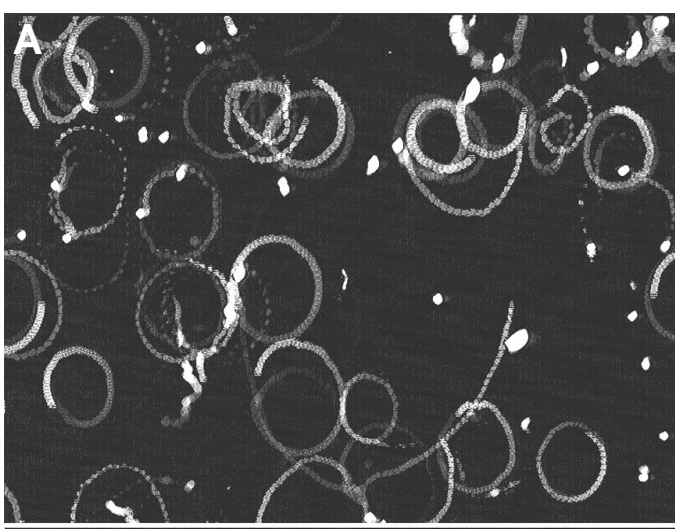

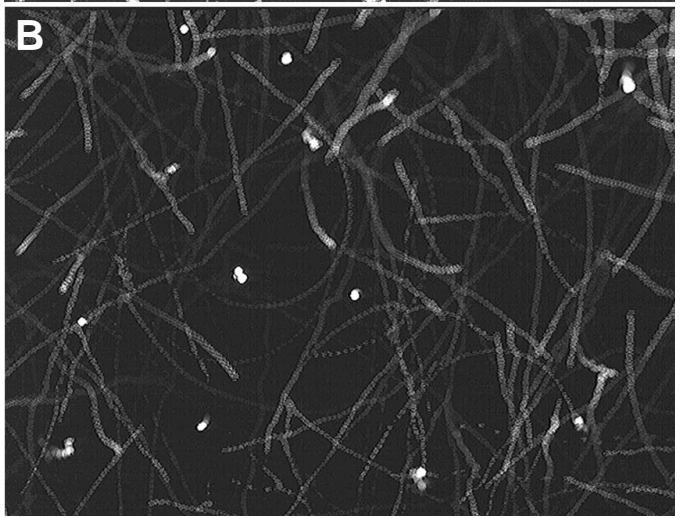

Fig. 5 (Left). Changes in $\left[\mathrm{Ca}^{2+}\right]_{\mathrm{i}}$ in Fluo-4-AM $(5 \mu \mathrm{M})$ and BAPTA-AM $(50 \mu \mathrm{M})$ loaded sperm exposed to sperm motility initiating factor (SMIF, $\mathbf{5 0} \mathbf{\mu g} / \mathbf{m l}$ ) and assessed in the fluorometer. (A) Tracings of sperm Fluo-4 fluorescence (counts per second, CPS). SMIF was added at the arrow for all samples. Sperm without BAPTA (0.05\% DMSO, 口) showed a normal [C $\left.\mathrm{Ca}^{2+}\right]_{i}$ response to SMIF. Sperm loaded with $25 \mu \mathrm{M}(\bullet), 50 \mu \mathrm{M}(\diamond)$, and $100 \mu \mathrm{M}(\mathbf{\Delta})$ BAPTA-AM showed progressive decreases in $\left[\mathrm{Ca}^{2+}\right]_{i}$ when SMIF was added. (B) Calculated concentrations in $\left[\mathrm{Ca}{ }^{2+}\right]_{i}$ for the different BAPTA-AM loading levels are shown. Sperm loaded with $100 \mu \mathrm{M}$ BAPTA-AM exhibited poor motility. However, sperm loaded with 25 and $50 \mu \mathrm{M}$ appeared to exhibit percent motility similar to that of control sperm.

Fig. 6 (Right). Sperm motility patterns collected using 1-2 s exposures with darkfield optics as described previously (Vines et al., 2002). (A) Sperm exposed to SMIF $(50 \mu \mathrm{g} / \mathrm{ml})$ show the typical circular trajectories. (B) Sperm pre-loaded with $50 \mu M$ BAPTA-AM and then exposed to SMIF show many more linear trajectories.

puter analysis of sperm motility patterns clearly showed that HSAPs elicit a more linear motility that is similar to the motility pattern induced by $\mathrm{Na}^{+}$-free ASW. Three different EV analyses, including net to gross displacement (shown in Fig. 2), as well as direction of travel and rate of change of direction (neither shown graphically), all demonstrated statistically significant differences between SMIF- and HSAP-induced trajectories. In sperm from other fish, different physiological compositions of the media result in varied motility patterns (linear versus circular; Boitano and Omoto, 1992). For invertebrate sperm, egg-derived molecules have been shown to alter sperm trajectories (Cook et al., 1994; Riffell et al., 2002; Kaupp et al., 2003; Wood et al., 2005; Böhmer et al., 2006); however, these are cases where molecules alter the trajectories of sperm that have already initiated motility due to dilution in the spawning media. An exception to this is ascidian sperm where an egg-derived motility initiator molecule is required for both sperm activation and chemotaxis (Yoshida et al., 2003). To our knowledge, the finding of an egg that possesses two distinct motility initiators, that each induce very different sperm trajectories, is novel.

Herring sperm, in the absence of egg-derived motility initiators, maintain their immotility across all environmentally relevant salinities due to a reverse $\mathrm{Na}^{+} / \mathrm{Ca}^{2+}$ exchanger (Vines et al., 2002). The only artificial ionic medium capable of initiating sperm motility in the absence of natural motility initiators is $\mathrm{Na}^{+}$-free ASW (with sodium chloride replaced by choline chloride) (Yanagimachi et al., 1992); in this medium, extracellular $\mathrm{Ca}^{2+}$ must be $\geq 1 \mathrm{mM}$ for motility initiation (Vines et al., 2002). It has been suggested that at salinities where extracellular $\mathrm{Na}^{+}$is low enough to allow $\mathrm{Na}^{+}$efflux and motility initiation, extracellular $\mathrm{Ca}^{2+}$ would be well below $1 \mathrm{mM}$ and motility could not occur. The two sperm motility initiators, HSAPs and SMIF, are known to require decreased salinity (1/2 strength seawater is optimal) for induction of motility (Yanagimachi et al., 1992; Morisawa et al., 1992; Pillai et al., 1993).

\section{Herring motility initiators increase different levels of $\left[\mathrm{Ca}^{2+}\right]_{i}$ in sperm}

It has been known for years that sperm motility initiation in herring sperm is dependent on extracellular $\mathrm{Ca}^{2+}$ (Yanagimachi, 1953; Yanagimachi and Kanoh, 1953; Yanagimachi et al., 1992), and more recently it has been shown that SMIF- and $\mathrm{Na}^{+}$-free ASW-induced motility initiation is in fact due to increases in $\left[\mathrm{Ca}^{2+}\right]_{i}$ 


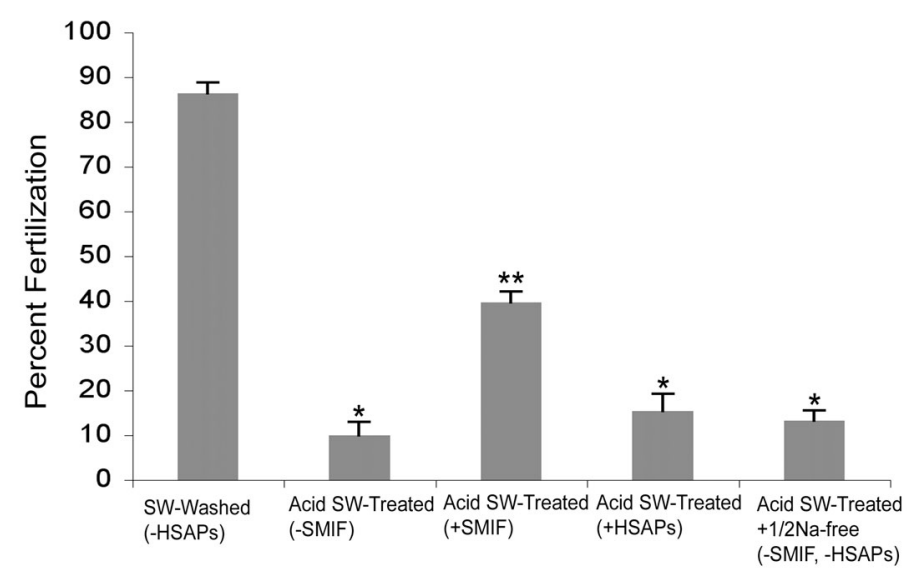

Fig. 7. Fertilization rescue experiments using eggs that had herring sperm activating proteins (HSAPs) and sperm motility initiating factors (SMIF) removed (see Materials and Methods). All treatments involved inseminated with the same concentration of sperm. Eggs that had HSAPs removed via extensive washing with 1/2 ASW (SW-treated) showed high fertilization rates. Acid ASW (acid SW-treated) eggs showed very low fertilization success as previously reported. The addition of SMIF $(50 \mu \mathrm{g} / \mathrm{ml})$ just as sperm were added rescued the acid SW-treated eggs, even though the fertilization rate was still suppressed compared to controls ( $p=0.042$, double asterisk). Acid SW-treated eggs by themselves or those treated with HSAPs $(50 \mu \mathrm{g} / \mathrm{ml})$ or $1 / 2 \mathrm{Na}^{+}$-free ASW showed significantly ( $p \leq 0.02$, single asterisks) decreased fertilization rates compared to controls (SW-treated), as well as to SMIF rescue treatments.

(Vines et al., 2002). In this study, we have shown that increases in $\left[\mathrm{Ca}^{2+}{ }_{i}\right.$ differ between HSAPs and SMIF, with SMIF inducing $\sim 4$ fold increase and HSAPs inducing $\sim 2$ fold increase. Previously it was shown that the increase in $\left[\mathrm{Ca}^{2+}\right]_{i}$ due to SMIF was entirely dependent on extracellular $\mathrm{Ca}^{2+}$ and that both reverse $\mathrm{Na}^{+} / \mathrm{Ca}^{2+}$ exchange, as well as the opening of voltage-gated $\mathrm{Ca}^{2+}$ channels, were responsible (Vines et al., 2002). It has been suggested that the $\left[\mathrm{Ca}^{2+}\right]_{i}$ increase in the presence of HSAPs and the C-terminal HSAPs peptide may be due in part to its release from intracellular $\mathrm{Ca}^{2+}$ stores since the $\mathrm{Ca}^{2+}$ channel antagonist nifedipine did not inhibit motility and only partially inhibited the increase in $\left[\mathrm{Ca}^{2+}\right]_{i}$ (Yoshida, 1998). It is possible that reverse $\mathrm{Na}^{+} / \mathrm{Ca}^{2+}$ exchange as well as only intracellular release of $\mathrm{Ca}^{2+}$ occur in sperm exposed to HSAPs, while SMIF induces activation of the reverse $\mathrm{Na}^{+} / \mathrm{Ca}^{2+}$ exchanger in addition to the opening of voltage-gated $\mathrm{Ca}^{2+}$ channels; this may be the reason there are higher levels of $\left[\mathrm{Ca}^{2+}\right]_{i}$ observed with sperm treated with SMIF. In other fish sperm, motility initiation involves either an influx of extracellular $\mathrm{Ca}^{2+}$ or its release from intracellular stores, or both (Boitano and Omoto, 1992; Krasznai et al., 2000, 2003; Morita et al., 2003: Hee etal., 2005; Alavi and Cosson, 2006).

The level of $\left[\mathrm{Ca}^{2+}\right]_{i}$ in sperm is known to be directly related to flagellar asymmetry and altered sperm trajectories (Boitano and Omoto, 1992; Kaupp et al., 2003; Wood et al., 2003; 2005; Böhmer et al., 2006). Our findings that HSAPs induce linear trajectories at relatively low $\left[\mathrm{Ca}^{2+}\right]_{i}$ while SMIF induces more circular trajectories at higher $\left[\mathrm{Ca}^{2+}\right]_{\mathrm{i}}$ levels are consistent with these other studies. Furthermore, sperm preloaded with BAPTA$A M$ and exposed to SMIF were found to induce a level of $\left[\mathrm{Ca}^{2+}\right]_{i}$ similar to that observed in sperm induced to swim with HSAPs or $\mathrm{Na}^{+}$-free ASW. These BAPTA-loaded sperm exhibited similar trajectories as the HSAPs/1/2 $\mathrm{Na}^{+}$-free ASW treated sperm; while we did not conduct computer analyses on these sperm, it is clear that manipulation of the $\left[\mathrm{Ca}^{2+}\right]_{\mathrm{i}}$ with BAPTA resulted in "SMIF-treated sperm" behaving more like "HSAP-treated sperm". We have made observations that sperm swimming in linear trajectories exposed to HSAPs changed their trajectories to circular upon addition of SMIF (unpublished data). At present, it is not known if combined exposure of sperm to both HSAPs and SMIF results in levels of $\left[\mathrm{Ca}^{2+}\right]_{\mathrm{i}}$ that are even above those observed with SMIF alone. SMIF induces a global increase in sperm $\left[\mathrm{Ca}^{2+}\right]_{\mathrm{i}}$ that includes the head, midpiece, and flagellum (Vines et al., 2002; this study), while HSAPs induced a $\left[\mathrm{Ca}^{2+}\right]_{\mathrm{i}}$ increase in just the head and midpiece. This could be related to the location of binding of the two initiators to the sperm surface: SMIF has been shown to bind over the entire sperm surface (with majority of binding to the midpiece region; Griffin et al., 1996), while HSAPs have been shown to bind only to the head of the sperm (not the midpiece or flagellum; Yoshida, 1998). This hypothesis remains to be tested.

Our data demonstrate that the ability of sperm to undergo a circular trajectory in the micropylar region may be critical for successful fertilization in herring. This is based on three lines of experimental evidence. First, HSAPs, which induce linear motility, were not capable of supporting fertilization in SMIF-free eggs. Second, this same lack of fertilization was also observed with $\mathrm{Na}^{+}$-free ASW, which also induces linear motility. Third, BAPTA-loaded sperm showed dramatic reductions in fertilization rates and these sperm also showed linear trajectories in the presence of SMIF. Taken together, these data demonstrate that adequate increases in $\left[\mathrm{Ca}^{2+}\right]_{i}$ are required for herring sperm to undergo the circular motility pattern observed in the micropylar region and subsequent penetration of the micropylar

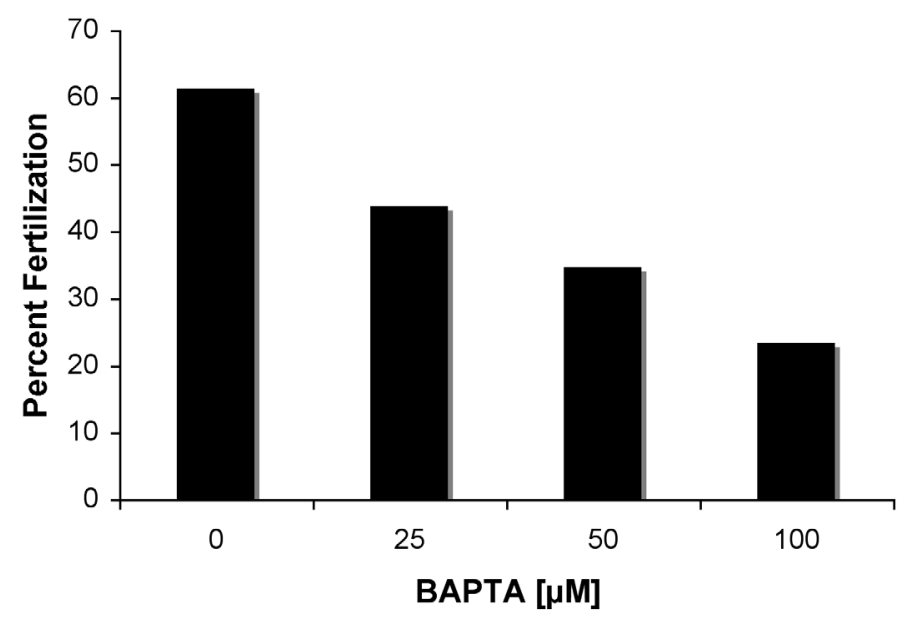

Fig. 8. Effects of BAPTA-AM (50 $\mu \mathrm{M})$ loading on sperm ability to fertilize eggs. Sperm exposed to solvent (0.05\% DMSO, "O") showed normal fertilization rates. Increasing BAPTA loading decreased fertilization rates. The $100 \mu \mathrm{M}$ BAPTA loaded sperm may have also showed decreased fertilization due to decreased motility. All treatments used the same sperm concentration $\left(5 \times 10^{5} / \mathrm{ml}\right)$ to fertilize 200 eggs in $30 \mathrm{ml}$ of ASW. 


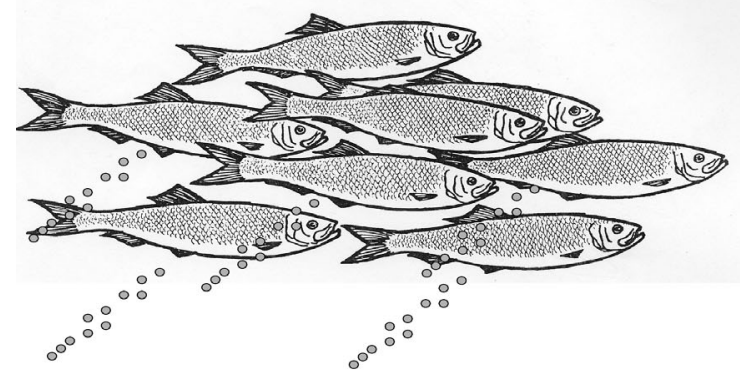

Fig. 9. Proposed model for herring sperm activating protein (HSAP) and sperm motility initiation factor (SMIF) induced motility and fertilization in herring. Sperm are not drawn to scale (they appear about 8x larger). Actual sizes are: eggs, 1 $\mathrm{mm}$ in diameter; sperm, 40 m in length. Spawning substrates include algae and rocks. (A) Eggs are released from females in water containing non-motile sperm. (B) Eggs adhere to substrate and HSAPs diffuse from the outer layer of the chorion. Diffusing HSAPs induce linear motility trajectories in sperm and increase sperm-egg collision frequency. (C) Sperm that contact SMIF in the micropylar region initiate circular trajectories due to elevated $\left[\mathrm{Ca}^{2+}\right]_{i}$. This trajectory maintains sperm in the micropylar region and is required for fertilization. As HSAPs dilute over time fewer motile sperm can be observed in the vicinity of eggs. See Discussion for details.

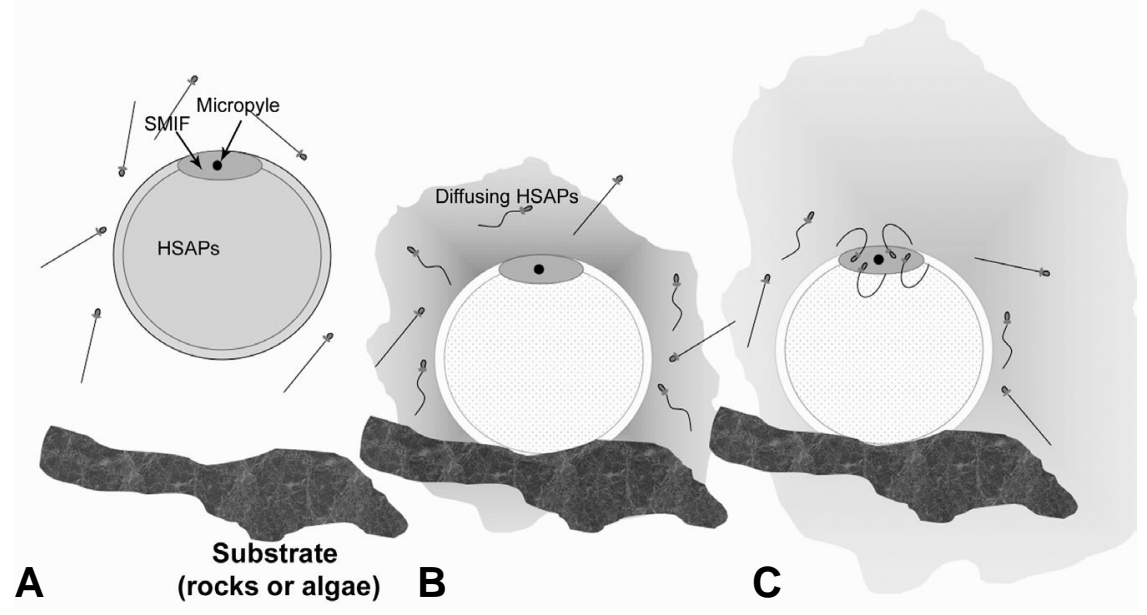

canal. It appears only SMIF is capable of facilitating this biologically relevant physiological response.

\section{Proposed model for role of herring egg-derived sperm motil- ity initiators}

Based on the results of experiments in the present study, as well as our previous investigations, we propose that sequential exposure to egg-derived motility initiators occurs during spermegg interactions. Pacific herring are primitive teleosts that spawn in large schools without physical interactions between sexes; this is considered ancestral to other teleost mating systems (Carolsfeld etal., 1997). It has been documented that male herring spawn first and the release of milt in the water attracts and induces spawning in females as well as other males (Hay, 1985; Carolsfeld et al., 1997). For example, Hay (1985) observed large regions of the coast with sperm in the water (known as "white water") with no egg deposition, and subsequently found that males were spent while females were only partially spent. Therefore, it would appear that in herring, some sperm in an immotile state are in the water for extensive periods of time prior to eggs being deposited.

In our proposed model, immotile sperm are present as eggs are deposited (Fig. 9A). These eggs would have HSAPs associated with the surface of the chorion except in the micropyle region where SMIF is localized. HSAPs would diffuse away from the chorion surface as eggs attach (via the adhesive coat) to substrates (algae, rocks), and HSAP-induced sperm motility could be initiated (Fig. 9B). This sperm motility would be linear and random, thereby increasing sperm-egg collision frequency. It should be noted that numerous in vitro observations of sperm in the vicinity of eggs, immediately upon immersion in seawater, have not reported motility except in the micropylar region (Yanagimachi and Kanoh, 1953; Yanagimachi, 1953; Yanagimachi 1957a,b; Yanagimachi et al., 1992). We assume that HSAPs are capable of inducing of active motility in vivo if the concentration of eggs at spawning is great enough. However, even if motility is not initiated at lower concentrations of HSAPs, these proteins may possess motility/fertilizationenhancing functions as they may "prime" the sperm for a more immediate and complete SMIF response. This is not unlike what has been proposed for other egg-derived signaling molecules associated with extracellular coats (Cherr et al., 1999; 2001; Mah et al., 2005). In a very short period following spawning, HSAPs would be expected to diffuse and dilute extensively such that they could be below their critical concentration for inducing motility; as such, there would be only limited numbers of sperm that would remain motile (linear trajectories) in the vicinity of the egg (Fig. 9C). However, sperm that have come into contact with SMIF in the micropylar region would now accumulate and be highly motile with circular trajectories (Fig. 9C). These sperm would have achieved a maximal level of $\left[\mathrm{Ca}^{2+}\right]_{i}$ and the circular motility maintains them in the micropylar region. Sperm that are in this trajectory as a result of repeated contact with SMIF rapidly enter the micropylar canal and fertilize the egg. While SMIF-induced circular motility is required for entry into the micropylar canal, we cannot rule out that an additional component such as a "sperm guidance factor" in the canal itself plays a role (Yanagimachi et al., 1992).

In summary, we have shown that both HSAPs and SMIF initiate herring sperm motility and that the sperm trajectories differ, with HSAPs being more linear and SMIF being more circular. These motility patterns correspond to differing levels of $\left[\mathrm{Ca}^{2+}\right]_{\mathrm{i}}$ increases above the level found in immotile sperm: SMIF is 2 times above the HSAPs-induced increase. The linear HSAP-induced trajectories were not able to support fertilization in the absence of SMIFinduced circular motility, indicating that asymmetric bending and elevated $\left[\mathrm{Ca}^{2+}\right]_{i}$ are required for fertilization. The proposed function of HSAPs in fertilization therefore appears to be increased collision frequency, which may be important for these broadcast spawning fish where individual male-female contact mating behavior may be minimal.

\section{Materials and Methods}

\section{Fish, seawater and chemicals}

Mature Pacific herring were caught by otter trawl or gill nets in either San Francisco or Tomales Bay, CA by the California Department of Fish 
and Game and transported on ice to the Bodega Marine Laboratory. Testis and ovaries were dissected and stored "dry" in individual culture plates at $4^{\circ} \mathrm{C}$ under moist conditions (Vines et al., 2002). Some experiments were conducted at the Hokkaido National Fisheries Research Institute, Kushiro, Japan, using herring collected from Akkeshi and Furen Lakes, as well as at the Onagawa Marine Fisheries Laboratory, Tohoku University, Japan, with fish from the Mangoku-ura (Matsushima Bay), Japan. All seawaters used were $1 / 2$ strength in order to match optimal ion composition for herring sperm motility, fertilization, and development (Griffin et al., 1998). Experiments used either $1 / 2$ strength artificial seawaters (ASW; $\mathrm{Na}^{+}$-free ASW) or $0.45 \mu \mathrm{m} \mathrm{1/2}$ strength filtered seawater (FSW) as previously described (Yanagimachi etal., 1992; Vines et al., 2002). Most chemicals were from Sigma Chemical (St. Louis, MO, USA) except where noted.

\section{Isolation of HSAPs and SMIF}

HSAPs were isolated according to Oda et al., (1995). Briefly, eggs were spread across a nylon mesh and allowed to incubate in $3 \mathrm{~L}$ of seawater, clarified by centrifugation, and the solution subjected to gel filtration. The active eluant was concentrated by ammonium sulfate precipitation followed by dialysis to desalt the HSAP fraction. The Cterminal HSAPs peptide was synthesized and purified by Sawady Technology Co. (Tokyo, Japan). SMIF was isolated and purified according to Pillai et al., (1993), Griffin et al., (1996) and Vines et al., (2002). Briefly, eggs were suspended and washed 3-5 times in 1/2 strength calcium and magnesium-free seawater containing $0.25 \%$ polyvinyl alcohol at $4^{\circ} \mathrm{C}$. Eggs were disrupted in this same medium with a Dounce homogenizer, the chorions allowed to settle out of solution, and washed free of egg cytoplasm with 4-5 exchanges of $1 / 2$ calcium-magnesium-free seawater, followed by washing with distilled $\mathrm{H}_{2} \mathrm{O}$. Chorions were either used immediately or lyophilized and stored at $-70^{\circ} \mathrm{C}$. SMIF was isolated by suspending the chorions in $1 / 2$ artificial seawater $(\mathrm{pH} 3.5)$ at $4^{\circ} \mathrm{C}$ for 30 minutes with periodic homogenization. The supernatant was centrifuged

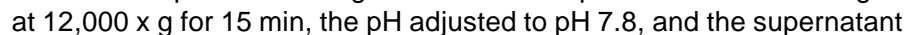
concentrated using $10 \mathrm{kDa}$ MW Centricon microconcentrator (Amicon Co., Beverly, MA). The retentate, SMIF, was used immediately or stored at $-70^{\circ} \mathrm{C}$.

\section{Sperm motility determination and analysis}

Sperm motility assessments were conducted at ambient temperature $\left(8-10^{\circ} \mathrm{C}\right)$ on microscope slides (multiwell immunofluorescence slides, Polysciences, Inc., Warrington, PA, USA) without coverglass. Typically, a 30-50 $\mu \mathrm{l}$ drop of medium was placed on the slides and then $0.5-1 \mu \mathrm{l}$ of dry sperm pipetted into the center of the well. Sperm that initiated motility were immediately visible leaving the concentrated sperm drop. All imaging was conducted in focal plane in the center of the drop of medium such that the interaction of sperm with surfaces was avoided. Motility was observed using an Olympus $\mathrm{BH} 2$ upright phase contrast microscope with a Peltier-cooled stage. Sperm were viewed using a $20 x$ objective lens either with phase contrast or darkfield optics. For qualitative scoring, sperm motility was assessed using the following qualitative index: $0=<25 \%$ motility, $1+=25-50 \%$ motility, $2+=50-75 \%$ motility, $4+=>75 \%$ motility (Pillai et al., 1993). For digital video capture, a Pixelink (Ottawa, Ontario Canada) PL-A661 monochrome Firewire camera with input to a Macintosh computer was used for capture at 30 frames/sec.

For computer analysis of motility, video images of herring sperm were analyzed using an Expert Vision (EV) motion analysis system (Motion Analysis Corporation, Santa Rosa, CA, USA). For obtaining the path data, $15 \mathrm{sec}$ of data at 30 frames per second was used. These capture times and frame rates are similar to those used by Boitano and Omoto (1992) as well as Katz and Davis (1987) who used the EV system for analysis of sperm motility. The path trajectories were superimposed on the raw video data to verify that the paths were correctly determined. Parameters analyzed with the EV system included: 1) percent motility; 2) speed (the mean and standard deviation of the mean for each path was extracted);
3) direction of travel; 4) rate of change of direction; and 5) net to gross displacement ratio. For some data sets, $t$-tests were used. Other data sets were not normally distributed and a Mann-Whitney Rank Sum Test was employed. In all cases, means of individual sperm for each treatment were used, and using this more conservative statistical approach, significant differences were considered more biologically relevant.

\section{Determination of intracellular calcium}

$\left[\mathrm{Ca}^{2+}\right]_{\mathrm{i}}$ was determined according to Vines et al., (2002). Briefly, sperm $\left(10^{7} / \mathrm{ml}\right)$ in herring Ringers (Yanagimachi et al., 1992) were loaded with either Fluo-4-AM or Fluo-3-AM (5 $\mu \mathrm{M}$ final concentration; Invitrogen Corp., Carlsbad, CA USA) for one h at $13^{\circ} \mathrm{C}$, centrifuged at $920 \times \mathrm{g}$ for 5 min each through a ringers $/ 10 \%$ Ficoll solution, followed by one more wash in ringers. Loaded sperm were placed in cuvettes containing FSW, ASW, or $\mathrm{Na}^{+}$-free ASW (sodium chloride replaced with choline chloride), an artificial initiator of herring sperm motility (Vines et al., 2002). A Photon Technology, Inc. (PTI) fluorescence spectrophotometer (New Brunswick, NJ USA) equipped with a temperature controlled cuvette holder was used with excitation 506, emission 526, and a slit width of $5 \mathrm{~nm}$. Following baseline stabilization, SMIF, HSAPs, or the C-terminal HSAPs peptide was added to cuvettes containing FSW or ASW cuvettes. Controls consisted of a comparable volume of $1 / 2 \mathrm{FSW}$ or ASW added to the cuvettes. $\left[\mathrm{Ca}^{2+}\right]_{i}$ was calculated using the equation $\left[\mathrm{Ca}^{2+}\right]_{i}=\left(\mathrm{F}-\mathrm{F}_{\min }\right) /$ $\left(F_{\max }-F\right) K d$, where $F_{\text {max }}=$ fluorescence in a sample after addition of $50 \mathrm{mM}$ digitonin, $F_{\text {min }}=$ fluorescence in 0.5 M EGTA, pH 8.5 in $1 \mathrm{M} \mathrm{Tris-HCl,} F=$ sample response, and $\mathrm{K}_{\mathrm{d}}=$ dissociation constant for the dye $(390 \mathrm{nM})$.

Experiments manipulating $\left[\mathrm{Ca}^{2+}\right]_{i}$ using BAPTA-AM utilized the same approach as described for Fluo-4-AM loading except in addition to Fluo4-AM, concentrations of glycine, N,N'-[1,2-ethanediylbis(oxy-2,1phenylene)]bis[N-[2- [(acetyloxy)methoxy]-2-oxoethyl]]-, bis[(acetyloxy) methyl] ester (BAPTA-AM) ranging from $25-100 \mu \mathrm{M}$ were included. $\left[\mathrm{Ca}^{2+}\right]_{\mathrm{i}}$ was determined for BAPTA-loaded sperm exposed to SMIF (or control FSW) using the PTI fluorometer as described above. These same sperm were used for determining the effects of increasing concentrations of BAPTA-AM on fertilization rates (see below).

Sperm loaded with Fluo-3-AM were imaged for changes in $\left[\mathrm{Ca}^{2+}\right]_{\mathrm{i}}$ using a scanning laser confocal microscope (Olympus Fluoview 500, Olympus Corp., Tokyo, Japan) mounted on an Olympus BX61WI fixed stage microscope equipped with water immersion fluorescence objectives (40x and 60x) and a Peltier-cooled stage.

\section{Assessment of fertilization}

To determine the role of HSAPs and SMIF in fertilization, the following experiments were conducted using gametes from three different females and males in separate trials. Eggs ( 200/dish) from ovaries were extensively washed in culture dishes using calcium-magnesium-free ASW, followed by washing (1L) with FSW over 30 min at $10^{\circ} \mathrm{C}$ in order to remove HSAPs. Removal of HSAP activity was confirmed by examining sperm motility in both the final wash solution as well as observation of sperm in the vicinity of a sample of washed eggs using a $4 x$ objective lens with darkfield optics. These eggs did show high SMIF activity in the micropyle regions even following extensive washing, as we have previously reported (Yanagimachi et al., 1992). Washed eggs were then treated with either 1/2 strength ASW, pH 3.5 for $30 \mathrm{~min}$, or treated in an identical manner with $1 / 2$ strength $\mathrm{ASW}, \mathrm{pH} 7.8$, at $10^{\circ} \mathrm{C}$. The solutions were removed and the acid ASW adjusted back to $\mathrm{pH} 7.8$, and assessed for sperm motility initiation activity. Only the acid ASW solution was active and this represented a typical SMIF extraction. Following washing (3x) with ASW, dishes (30 ml ASW containing 200 eggs) were treated in four ways: 1$)$ eggs fertilized with sperm $\left(5 \times 10^{5} / \mathrm{ml}\right)$ in ASW (control); 2) eggs fertilized with sperm with HSAPs $(50 \mu \mathrm{g} / \mathrm{ml}$ final) added to the eggs; 3 ) eggs fertilized with sperm with SMIF (50 $\mu \mathrm{g} / \mathrm{ml}$ final) added; and 4) eggs fertilized with sperm in a solution of $\mathrm{Na}^{+}$-free ASW. Following a 15 min coincubation, eggs were washed $3 x$ with ASW, fixed in $1 \%$ paraformaldehyde in ASW, and the percentage of eggs in all four treatments were 
enumerated. Sperm $(5 \times 105 / \mathrm{ml})$ pre-loaded with differing amounts of BAPTA-AM were also used in experiments using freshly washed eggs ( 200/dish) with $30 \mathrm{ml}$ ASW in order to assess the effects of manipulating $\left[\mathrm{Ca}^{2+}\right]_{\mathrm{i}}$ and trajectory changes on fertilization success.

\section{Statistical analyses}

All statistical analyses were conducted using either Sigma Stat 2.0 (Systat Software, Inc., San Jose, CA USA) or Excel 2003 (Microsoft Corp., WA USA). T-tests, non-parametric analyses (Mann-Whitney Rank Sum Test), and analysis of variance were all used for different data sets. $P$ values $\leq 0.05$ were considered statistically significant.

\section{Acknowledgements}

The authors wish to thank Dr. Tadashi Andoh (Hokkaido National Fisheries Research Institute), Heather Brown (UC Santa Cruz), and Dr. Sumio Ishijima (Tokyo Institute of Technology) for discussions and technical assistance. We also thank Ken Oda and Tom Moore of the California Department of Fish and Game for assistance with fish collections. This research was supported by National Science Foundation Grant IBN-9904711 and by a National Science Foundation International Travel Supplement.

\section{References}

ALAVI SMH, COSSON J (2006) Sperm motility in fishes. (II) Effects of ions and osmolality: A review. Cell Biol Int 30:1-14.

BÖHMER M, VAN Q, WEYAND I, HAGEN V, BEYERMANN M, MATSUMOTO M, HOSHI M, HILDEBRAND E, KAUPP UB (2005) $\mathrm{Ca}^{2+}$ spikes in the flagellum control chemotactic behavior of sperm. EMBO J24:2741-2752.

BOITANO S, OMOTO CK (1992) Trout Sperm Swimming Patterns and Role of Intracellular $\mathrm{Ca}^{2+}$. Cell Mot Cytoske/21:74-82.

CAROLSFELD J, TESTER M, KREIBERG H, SHERWOOD NM (1997) Pheromone-Induced Spawning of Pacific Herring I. Behavioral Characterization. Hormones Behav 31:256-268.

CHERR GN, YUDIN AI, LI M-W, VINES CA, OVERSTREET JW (1999) Hyaluronic acid and the cumulus extracellular matrix induce increases in intracellular calcium in macaque sperm via the plasma membrane protein $\mathrm{PH}-20$. Zygote 7:211-222.

CHERR GN, YUDIN AI, OVERSTREET JW (2001) The dual functions of GPIanchored PH-20: Hyaluronidase and intracellular signaling. Matrix Bio/20:515525.

COOK SP, BROKAW CJ, MULLER CH, BABCOCK DF (1994) Sperm chemotaxis: Egg peptides control cytosolic calcium to regulate flagellar responses. Dev Biol 165:10-19.

DARSZON A, LABARCA P, NISHIGAKI T, ESPINOSA F (1999) Ion Channels in Sperm Physiology. Physiol Rev 79:481-510.

DETWEILER C, THOMAS P (1998) Role of ions and ion channels in the regulation of Atlantic croaker sperm motility. J Exp Zoo/281:139-148.

GRIFFIN FJ, VINES, CA, PILLAI MC, YANAGIMACHI R, CHERR G.N. (1996) Sperm motility initiation factor is a minor component of the Pacific herring egg chorion. Devel Growth Differ 38:193-202.

HAY D (1985) Reproductive biology of the Pacific herring (Clupea harengus pallasi). Can J Fish Aquat Sci42(Suppl 1):111-126.

HEE K, HEE K, MORISAWA M, CHOI KS (2005) Cell signaling mechanisms of sperm motility in aquatic species. J Micro Biotech 15(3):665-671.

KATZ DF, DAVIS RO (1987) Automatic analysis of human sperm motion. J Androl 8:170-181.

KAUPP UB, SOLZIN J, HILDEBRAND E, BROWN JE, HELBIG A, HAGEN V, BEYERMANN M, PAMPALONI F, WEYAND I (2003) The signal flow and motor response controlling chemotaxis of sea urchin sperm. Nat Cel/ Bio/5:109-117

KRASZNAIZ, MORISAWA M, KRASZNAI ZT, MORISAWA S, INABA K, BAZSANE ZK, RUBOVSKY B, BODNAR B, BORSOS A, MARIAN T (2003) Gadolinium, a mechano-sensitive channel blocker, inhibits osmosis-initiated motility of seaand freshwater fish sperm, but does not affect human or ascidian sperm motility.
Cell Motil Cytoske/55:232-243.

KRASZNAI Z, MARIAN T, IZUMI H, DAMJANOVICH S, BALKAY L, TRON L, MORISAWA M (2000) Membrane hyperpolarization removes inactivation of $\mathrm{Ca}^{2+}$ channels, leading to $\mathrm{Ca}^{2+}$ influx and subsequent initiation of sperm motility in the common carp. Proc Nat Acad Sci, USA 97:2052-2057.

MAH S, SWANSON WJ, VACQUIER VD. (2005) Positive selection the carbohydrate recognition domains of sea urchin sperm receptor for egg jelly (suREJ) proteins. Mol Biol Evol22(3):533-541.

MORISAWA M, AND SUZUKI K (1980) Osmolality and potassium ion: Their roles in initiation of sperm motility in teleosts. Science 210:1145-1147.

MORISAWA M, SUZUKI K, SHIMIZU H, MORISAWA S, YASUDA, K (1983) Effects of osmolality and potassium on motility of spermatozoa from freshwater cyprinid fishes. J Exp Biol107:95-103.

MORISAWA M, SUZUKI K, MORISAWA S (1983) Effects of potassium and osmolality on spermatozoan motility of salmonid fishes. JExp Bio/107:105-113.

MORISAWA, M (1985) Initiation of sperm motility at spawning in teleosts. Zool Sci 2:605- 615.

MORISAWA M, TANIMOTO S, OHTAKE H (1992) Sperm-activating proteins from unfertilized eggs of the Pacific herring, Clupea pallasi. J Exp Zoo/264:225-230.

MORISAWA, M (1994) Cell signaling mechanisms for sperm motility. Zool. Sci11: 647-662.

MORITA M, TAKEMURA A, OKUNO M (2003) Requirement of $\mathrm{Ca}^{2+}$ on activation of sperm motility in euryhaline tilapia Oreochromis mossambicus. J Exp Biol 206:913-921.

ODA S, MORISAWA M (1993) Rises of intracellular $\mathrm{Ca}^{2+}$ and $\mathrm{pH}$ mediate the initiation of sperm motility by hyperosmolality in marine teleosts. Cell Motil Cytoske/25:171-178.

ODA S, IGARASHI, Y, OHTAKE H, SAHAI K, SHIMUZU, N, MORISAWA M. (1995) Sperm activating proteins from unfertilized eggs of the pacific herring, Cluepa pallasi. Develop Growth Differ, 37: 257-261

ODA S, IGARASHI Y, MANAKA K-I, KOIBUCHI N, SAKAI-SAWADA M, SAKAI K, MORISAWA M, OHTAKE H, SHIMUZU N (1998) Sperm-activating proteins obtained from the Herring eggs are homologous to trypsin inhibitors and synthesized in follicle cells. Develop Bio/204:55-63.

OHTAKE H (2003) Sperm activating proteins obtained from the herring eggs. Fish Physiol Biochem 28:199-202.

PILLAI MC, SHIELDS TS, YANAGIMACHI R, CHERR GN (1993) Isolation and partial characterization of the sperm motility initiating factor from the eggs of the Pacific herring, Clupea pallasi. J Exp Zool, 265: 336-342.

RIFFELL JA, KRUG PJ, ZIMMER RK (2002) Fertilization in the sea: the chemical identity of an abalone sperm attractant. J Exp Bio/205:1439-1450.

SUZUKI"R. (1958) Sperm activation and aggregation during fertilization in some fishes I. Behavior of spermatozoa around the micropyle. Embryologia 4:93-10 2.

VINES CA, YOSHIDA K, GRIFFIN FJ, PILLAI MC, MORISAWA M, YANAGIMACHI R, CHERR GN (2002) Motility Initiation in Herring Sperm is Regulated by Reverse Sodium-Calcium Exchange. Proc Nat Acad Sci, USA 99:2026-2031.

WOOD CD, DARZSON A, WHITAKER M (2003) Speract induces calcium oscillations in the sperm tail. $J$ Cell Bio/161:89-101.

WOOD CD, NISHIGAKI T, FURUTA T, BABA SA, DARSZON A (2005) Real-time analysis of the role of $\mathrm{Ca}^{2+}$ in flagellar movement and motility in single sea urchin sperm. J Cell Biol, 169:725-731.

YANAGIMACHIR (1953) Effect of environmental salt concentrations on fertilizability of herring gametes. J Facult Sci, 11: 481-486.

YANAGIMACHI R (1957a) Some properties of the sperm activating factor in the micropyle area of the herring egg. Annot Zool Jap, 30:114-119.

YANAGIMACHI R (1957b) Studies of fertilization of Clupea pallasi. III. Manner of sperm entrance in to the egg. Zool Mag (Japan) 66: 222-225.

YANAGIMACHI R, KANOH Y (1953) Manner of sperm entry in herring egg, with special reference to the role of calcium ions in fertilization. J Fac Sci Hokkaido 11: 487-494.

YANAGIMACHI R., CHERR GN, PILLAI MC, BALDWIN JD (1992) Evidence suggesting the presence of a sperm-attracting substance around the micropy- 
les of salmonid and herring eggs. Growth Develop Differ 34: 447-461.

YOSHIDA, K. (1998) The study on the mechanism of sperm activation by spermactivating proteins in the Pacific herring, Clupea pallasi. Doctoral thesis, Univ. of Tokyo.
YOSHIDA M, MURATA M, INABA K, MORISAWA M (2002) A chemoattractant for ascidian spermatozoa is a sulfated steroid. Proc Nat Acad Sci, USA 99:1483114836.

\section{Related, previously published Int. J. Dev. Biol. articles}

See our recent Special Issue Developmental Biology in Poland edited by Tarkowski, Maleszewski and Kloc at: http://www.ijdb.ehu.es/web/contents.php?vol=52\&issue=2-3

See our recent Special Issue Ear Development edited by Fernando Giraldez and Bernd Fritzsch at: http://www.ijdb.ehu.es/web/contents.php?vol=51\&issue=6-7

The use of poly-L-lysine to facilitate examination of sperm entry into pelagic, non-adhesive fish eggs Tadashi Andoh, Takahiro Matsubara, Tatsuo Harumi and Ryuzo Yanagimach Int. J. Dev. Biol. (2008) 52: 753-757

\section{Regionalized calcium signaling in zebrafish fertilization}

Dipika Sharma and William H. Kinsey

Int. J. Dev. Biol. (2008) 52: 561-570

The role of ion fluxes in polarized cell growth and morphogenesis: the pollen tube as an experimental paradigm Erwan Michard, Filipa Alves and José A. Feijó Int. J. Dev. Biol. (2008) 52: doi: 10.1387/ijdb.072296em

An activating mutation in the PDGF receptor-beta causes abnormal morphology in the mouse placenta Camilla Looman, Tong Sun, Yang Yu, Agata Zieba, Aive Ahgren, Ricardo Feinstein, Henrik Forsberg, Carina Hellberg, Carl-Henrik Heldin, XiaoQun Zhang, Karin Forsberg-Nilsson, Nelson Khoo, Reinald Fundele and Rainer Heuchel Int. J. Dev. Biol. (2007) 51: 361-370

The dual role of chorion peroxidase in Bactrocera oleae chorion assembly Ourania A. Konstandi, Issidora S. Papassideri, Dimitrios J. Stravopodis, Marianna H. Antonelou, Christos A. Kenoutis, Despina C. Stefanidou and Lukas H. Margaritis Int. J. Dev. Biol. (2006) 50: 543-552

Visualization of primordial germ cells in vivo using GFP-nos1 3'UTR mRNA Taiju Saito, Takafumi Fujimoto, Shingo Maegawa, Kunio Inoue, Minoru Tanaka, Katsutoshi Arai and Etsuro Yamaha

Int. J. Dev. Biol. (2006) 50: 691-700

Mechanical control of tissue morphogenesis during embryological development Donald E. Ingber

Int. J. Dev. Biol. (2006) 50: 255-266

Primordial germ cell migration Kathleen Molyneaux and Christopher Wylie Int. J. Dev. Biol. (2004) 48: 537-543

The Wnt connection to tumorigenesis Jürgen Behrens and Barbara Lustig Int. J. Dev. Biol. (2004) 48: 477-487

Studies of the mechanism of amniotic sac puncture-induced limb abnormalities in mice.

$\mathrm{M} \mathrm{H}$ Kaufman and $\mathrm{H} \mathrm{H}$ Chang

Int. J. Dev. Biol. (2000) 44: 161-175

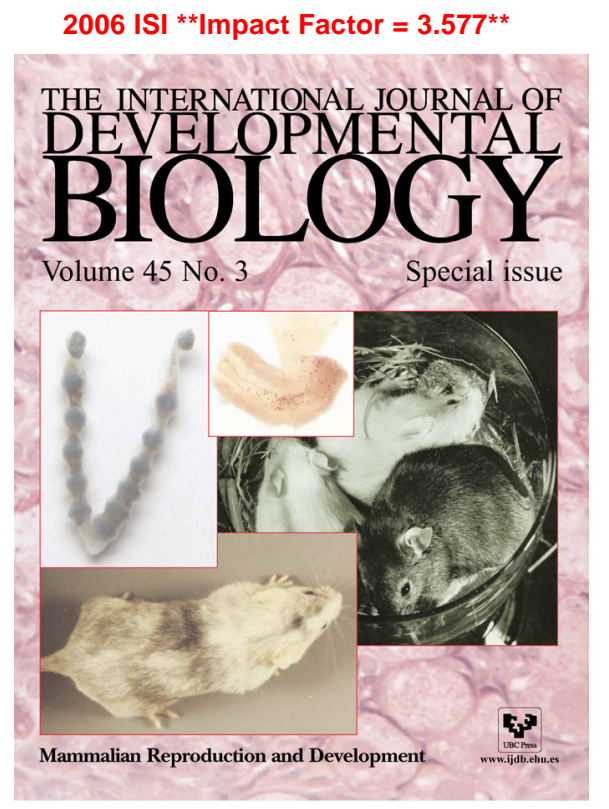

